\title{
Investigating the factors of difficulty in the Implementation of Differentiated Instruction in Greek Primary Education
}

\author{
Maria Sakellariou ${ }^{1}$, Polyxeni Mitsi $^{2}$ and Emmanouil Konsolas ${ }^{3}$ \\ ${ }^{1}$ Department of Early Childhood Education, University of loannina, Greece ${ }^{2}$ \\ Department of Early Childhood Education, University of Ioannina, Greece \\ ${ }^{3}$ Department of PreSchool Education Sciences and Educational Design, University of the
}

Aegean, Greece

\begin{abstract}
.
Differentiation of teaching and learning is a modern approach to the design and organization of the whole teaching process in mixed ability classrooms (Koutselini, 2008, Theofilides, 2008, Tomlinson, 2003).

The purpose of this paper is to highlight the difficulties in the practical implementation of differentiated instruction in Greek kindergarten and primary schools. For the collection of the data, a structured questionnaire was provided to 306 kindergarten and primary school teachers in the region of Epirus in Greece who stated that they possess the theoretical framework of differentiated instruction and its implementation process. The survey's findings highlight the basic difficulties faced in implementing differentiation. The data, although limited, are a trigger for further exploration of the issue of providing opportunities and supportive structures to teachers to effectively use in practice the differentiation of teaching and learning.
\end{abstract}

Keywords: Difficulties, Differentiated Instruction, Teachers

\section{Introduction}

The challenges of today's competitive, pluralist and multicultural society require that the reformulation and redefinition of teacher's role. Teachers are called upon to reflect, renew and change the personal practices and to adopt teaching frameworks that favor acceptance of individual differentiation, respect and participation. They should also pursue the implementation of actions that promote lifelong learning (Kanakis, 2006). Differentiation of teaching is probably the most realistic proposition in the demand for child-centered individualization practices and seems to respond dynamically to the need for teaching effectiveness in modern classrooms (Vastaki, 2010). The necessity and the imperatives of pedagogical science call for differentiated instruction not as a panacea, but as a link between teaching and social justice and professional moral commitment in order to achieve the elimination of student inequalities and the maximization of learning outcomes for each student (Valiandes \& Neophytou, 2017).

According to Tomlinson (2014) "differentiation" means adaptation of teaching to meet the different needs of students. It is the reformation of the learning process by applying alternative teaching methods to make it satisfactory in relation to students' learning readiness, requirements and learning profile. The teacher's different way of approaching and teaching to each student or 
group of students, the continuous assessment and the flexibility in grouping are basic elements of Differentiated Instruction. The main characteristic of Differentiated Instruction is that it treats students as separate biographies rather than as copies of the same image and aims to cognitively meet the needs of each student (Koutselini, 2006). It is noted, however, that Differentiated Instruction is not a ready specific recipe for implementation, it is not a didactic strategy, it is not another teaching model but it is more of a "other" way of thinking about didactic practice that affects teachers in the approach of teaching, learning, rules in the classroom, teaching time management, curriculum implementation, and assessment of the teaching work (Tomlinson, 2014). The teacher's role is decisive and the responsibility for the successful achievement and implementation of the differentiation is high (Valiandes \& Koutselini, 2009; Valiandes \& Koutselini, 2008). Differentiated Instruction is planned and implemented according to the level of readiness, interests, (Tomlinson, 2003) the socio-economic and cultural background and the different psychoemotional characteristics of each student (Koutselini, 2008; Koutselini \& Valiandes, 2009).

A number of researches internationally refer to the effectiveness of the implementation of differentiated instruction by pointing out the effective activation of the psychological potential of each student (Tomlinson, 2005; Broderick et al., 2005; Lewis \& Batts, 2005; Anderson, 2007; Carolan \& Guinn, 2007; Douglas et al. , 2008; King-Shaver, 2008; Wormeli, 2011; Valiandes, 2015). On the other hand, teachers claim that enrich their knowledge of teaching strategies, acquire experience, exploit alternative and innovative teaching approaches and improve their role in responding to the demands of modern educational reality (Tomlinson, 2014).

\section{Difficulties during the implementation of differentiated instruction in the educational process}

Strengthening the teacher's pedagogical role for being flexible in redefining and adapting teaching process is crucial and seems to bring significant benefits to all the members of the educational community (Koutselini, 2014). In order to apply differentiated instruction, the teacher is not completely oriented towards the content and learning object, to fill learning gaps and to address deficiencies but focuses on the needs, interests and personal profile of all students (Koutselini \& Patsalidou, 2015). The transition from theory to practice has fostered skills in designing and implementing differentiation, as well as enhancing teachers' self-confidence, satisfaction and enthusiasm by maximizing learning outcomes (Stavrou Erotokritou \& Koutselini, 2016). Teacher's reflection on the design and practical implementation of differentiation has prompted the development of consciousness, reflection and focus on the teaching process, the enhancement of metacognition on didactic design and the effectiveness of teaching practices. In a research conducted about the effectiveness of implementing differentiated instruction in mixed-ability classrooms, teachers claimed that by differentiation, they found that they developed further the analytical planning skills of their teaching (Valiandes, 2015).

Taking into consideration the widespread dissemination of differentiation, especially in recent years, notably through scientific conferences, scientific articles, and training programs, several teachers have attempted to somehow differentiate their teaching without, however, having a systematic approach (Valiandes \& Neophytou, 2017) but an occasional 
differentiation of goals and activities. The adaptation of their teaching relates mainly to the number of exercises depending on the learning level and the reduction of the curriculum's degree (De Neve, Devos \& Tuytens, 2015; Smit \& Humpert, 2012).

However, researches have shown that a large number of teachers do not know how to differentiate teaching, and basically they do not possess the theoretical background of differentiation (Callahan, Tomlinson, Moon, Brighton \& Hertberg, 2003; Valianti, 2015). But even if they know how to apply differentiation to mixed ability classrooms, they often face difficulties (Roy, Guay, Valois, 2012). In researches, it is often mentioned that teachers who differentiate their teaching they encounter difficulties in flexible grouping and in alternative ways of assessing (Santangelo \& Tomlinson, 2012; Smit \& Humpert, 2012).

As main difficulties to the implementation of differentiation, teachers report the limited preparation time, the workload, the large number of students per class, the lack of infrastructure and supportive tools, the incomplete and continuous knowledge but also the lack of motivation (Chan, Chang, Westwood \& Yuen, 2002; Scott, Vitale \& Masten, 1998; Westwood, 2002; Nicholas, 2013; Tobin \& Tippett, 2013; Valiandes \& Neophytou, 2017). The school principal, the existing legislation, the capabilities and requirements of the curriculum considerably restrict the implementation of differentiation according to the teachers (De Neve et al., 2015; Smit \& Humpert, 2012).

Researches also point out that teachers who differentiate their teaching can not apply it for a long time (Robinson \& Maldonado, 2014; Schumm \& Vaughn, 1991; Simpson \& Ure, 1994; Ysseldyke, Thurlow, Wotruba \& Nania, 1990; Westwood, 2001).

Teachers often choose to adopt characteristics and practices that are familiar to them from their student lives, from the standards of their own teachers, and form an image or model of a teacher who seeks to apply themselves (Cole \& Knowles, 1993). Among the reasons for the low and modest level of implementation of differentiated teaching, teachers argue that they usually follow their own way of teaching as they are not really aware of the actual implementation process (Yenmez \& Ozpmar, 2017). In addition, there seems to be a significant deviation between beliefs and practices, which demonstrates that theory deviates significantly from practice and ultimately theoretical knowledge from practical application (Wang et al., 2008).

The difficulties in implementing differentiated teaching and learning need to be faced effectively in order to enhance scientific and pedagogical dialogue and reflection on the further implementation and exploitation of alternative teaching practices and differentiated instruction in day-to-day school practice. A key priority is sufficient training of differentiation to teachers in order to enrich knowledge, acquire skills, change perceptions and enhance their self-confidence in the promotion of new teaching practices (Pandeliadou, Chideridou-Mandari, Papa, 2017). The participation of training programs can serve as an aid to changing teachers' beliefs and teaching practices (Cakir \& Alici, 2009; Wan, 2016). References on the teacher's professional development suggests that traditional practices of professional assistance in the form of conferences, lectures or some workshops may enhance teachers' knowledge and skills but do not work effectively in the application of alternative teaching practices (Boyle, Lamprianoy \& Boyle , $2005 \bullet$ Hanushek, $2005 \bullet$ Koellner \& Jacobs, 2015). The continuous training and the familiarity with the use of alternative and innovative techniques and strategies is likely to encourage teachers to apply differentiated 
instruction (Rodriguez, 2012). Teachers, for their training on differentiation issues, as reported by research data, seek training (Rodriguez, 2012; Sakellariou \& Mitsi, 2017) and are willing to attend it (Njagi, 2014).

This research is part of the wider reflection on the deviation of theoretical training and the practical application of innovative alternative teaching practices by teachers. In particular, the aim of this research was to highlight the difficulties faced by the Greek kindergarten and primary school teachers in implementing differentiated teaching and learning in the didactic process.

\section{Research methodology}

\subsection{Sample}

The sample of this survey is teachers in kindergartens and primary schools in the region of Epirus in Greece. We followed the random sampling technique according to which each subject of the population has the same probability of choice. In the research responded 306 kindergarten and primary school teachers.

\subsection{Period of the research}

The research was conducted during the period June to September of this year 2018.

\subsection{Method of data collection and analysis}

The questionnaire used in this research included questions about the demographics of the participants, multiple choice questions, Likert type 5 -level questions, open-ended questions as well as hierarchy questions. Prior to the collection of the survey data, a pilot application and correction of the tool was made. The internal consistency index of the scale found for the medium is judged to be very high, Cronbach's a =, 94 (Cohen et al., 2007).

During the descriptive statistical analysis of the research data it was found that the participants' answers did not show a smooth distribution. The quantized asymmetry of the skewness actually varied from $\gamma 1=-1,36$ to $\gamma 1=1,38$. The Kolmogorov-Smirnov criterion (Dytham, 2011) was used to check the distribution of the values of the study variables. Respondents' responses, as found, show a statistically significant deviation from regularity, $D(306)=1.82 ; p<0.01$ to $D(306)=5.05 ; p<, 001$. For these reasons it was considered necessary to use non-parametric statistical criteria for inductive statistical analysis.

\subsection{Limitations of research}

In case of this survey the basic restriction is that the taken sample of elementary schools of a single prefecture of the Epirus region.

\subsection{Data Presentation}

In the research responded 306 teachers, 35 men (11.4\%) and 271 women (88.6\%). The average years of working in education was 10 to 20 years for the majority of the sample (SD $=0.925$ ). The sample, based on the mode of taking, is considered "convenient" (Cohen et al., 2007). Table 1 shows the frequencies of age groups in the sample.

\begin{tabular}{ccc}
\hline Age Group & Frequency & Percentage \\
\hline $20-30$ years & 11,9 & 11,9
\end{tabular}




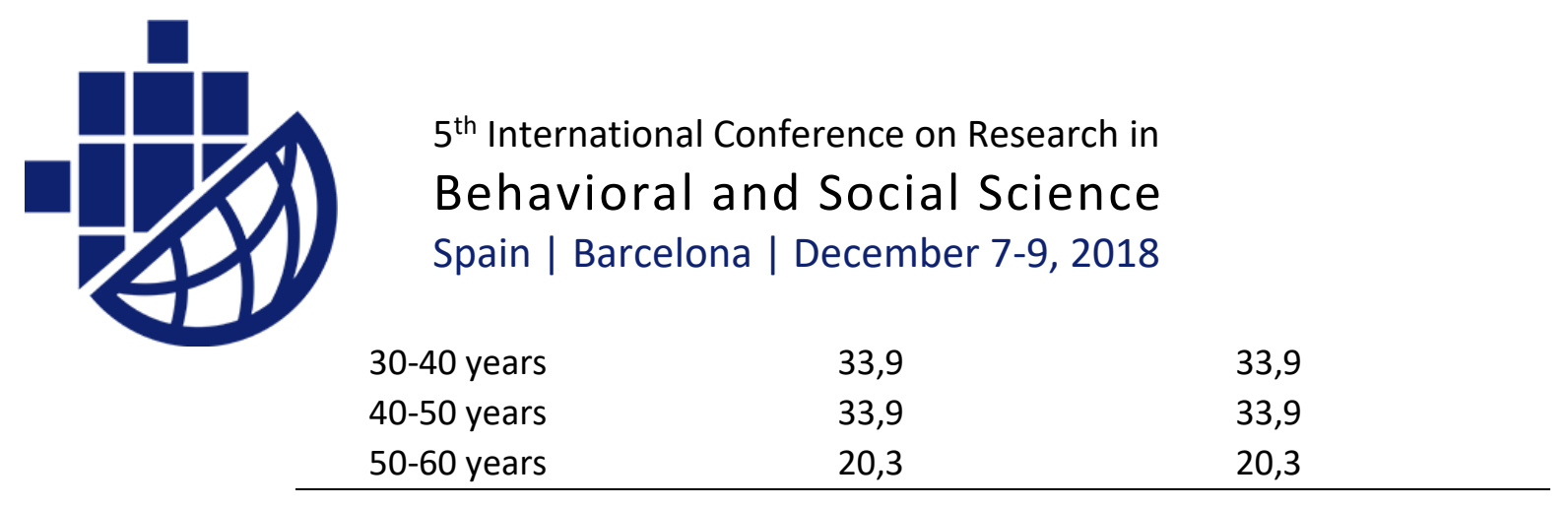

Table 1: Frequencies and percentages from the age group of the sample $(n=306)$

From the 306 participants in the survey, 182 (59.5\%) are primary school teachers, while the remaining 124 (40.5\%) belong to the kindergartens (Table.1).

\begin{tabular}{|l|r|r|r|r|}
\hline & & & & Cumulative \\
& Frequency & Percent & Valid Percent & Percent \\
\hline Valid Primary school teachers & 182 & & 59,5 & \\
Kindergarten teachers & 124 & 56,2 & 40,5 & 59,5 \\
Total & 306 & 38,3 & 100,0 & 100,0 \\
Missing System & 18 & 94,4 & & \\
& 324 & 5,6 & & \\
Total & & 100,0 & & \\
\hline
\end{tabular}

Table 1. Participants

The $77.8 \%$ of the sample works in public schools and $22.2 \%$ in private schools. As for the working years the majority of the sample, $41.5 \%$ work in education from $11-20$ years. The overwhelming majority, $89.2 \%$, speak fluently the English language. Teachers seem to have a good knowledge of computers.

Regarding the training provided by the teachers, $33.3 \%$ often and $32 \%$ always attend conferences, training sessions or training programs. Indeed, $62.1 \%$ responded that they attend approximately $3-$ 5 conferences, workshops or training sessions per year. $60.8 \%$ said they have never attended a conference abroad. The majority of the sample, $60.5 \%$, claimed that they are always willing to be educated on issues related to their work. $96.4 \%$ of the sample responded positively to the expression of interest in attending a future seminar, conference or workshop on the educational project. Teachers are informed for upcoming conferences, workshops or seminars from (94.4\%) the school and (63.4\%) from the internet.

Regarding teaches' familiarization with differentiated instruction, it appears that $70.6 \%$ claim that they know the theoretical background, while $69.6 \%$ claim that they know how to apply it in practice. From the sample of the survey $33 \%$ apply differentiated instruction 
sometimes, $30.4 \%$ often while $27.5 \%$ never. The difficulties encountered by teachers who have applied differentiated instruction are depicted in table 2 below.

\begin{tabular}{|l|l|}
\hline Difficulties in applying differentiation at school & $\begin{array}{l}\text { Valid } \\
\text { Percent }\end{array}$ \\
\hline I have difficulties in organizing and designing differentiation & $30,7 \%$ \\
\hline I feel insecure for the result of my lesson & $12,1 \%$ \\
\hline I feel anxiety for the parents' reaction & $8,5 \%$ \\
\hline Lack of teaching time & $43,8 \%$ \\
\hline The preparation is very demanding & $35,7 \%$ \\
\hline Many students per classroom & $65,4 \%$ \\
\hline Lack of supportive tools and equipment & $73,2 \%$ \\
\hline Lack of motivation & $26,5 \%$ \\
\hline Difficult school program & $46,4 \%$ \\
\hline Other reasons......... & $4,3 \%$ \\
\hline
\end{tabular}

Table 2. Difficulties in

applying differentiation at school

The reasons given by the teachers were the students' lack of familiarization with alternative teaching strategies and their difficulty in group working.

Teachers who responded that they prefer to use the traditional and usual way of teaching belong to $32.4 \%$ of the sample. From the teachers who applied Differentiated Instruction, $17.6 \%$ claimed that they never encountered any difficulties, $35.6 \%$ rarely, $32.6 \%$ sometimes and $14.2 \%$ always. By correlating primary school and kindergarten teachers with the difficulties encountered, there is no statistically significant difference. A statistically significant difference, however, was observed in relation to the level of education and the difficulties encountered by teachers in the implementation of differentiated instruction. The data showed that the teachers who own master degrees encountered comparatively fewer obstacles than their colleagues (bar graph 1 ).

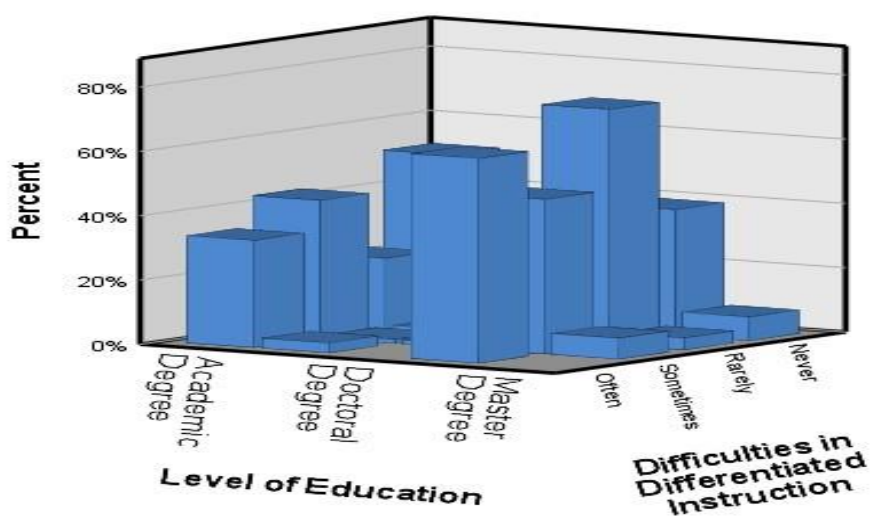


Bar graph 1. Level of Education -Difficulties in the implementation of Differentiated Instruction

The stressful curriculum is shown by the statistical analysis that it is a major obstacle to the implementation of differentiation more for primary school teachers $(30.4 \%)$ than for kindergarten teachers (16\%) (bar graph 2)

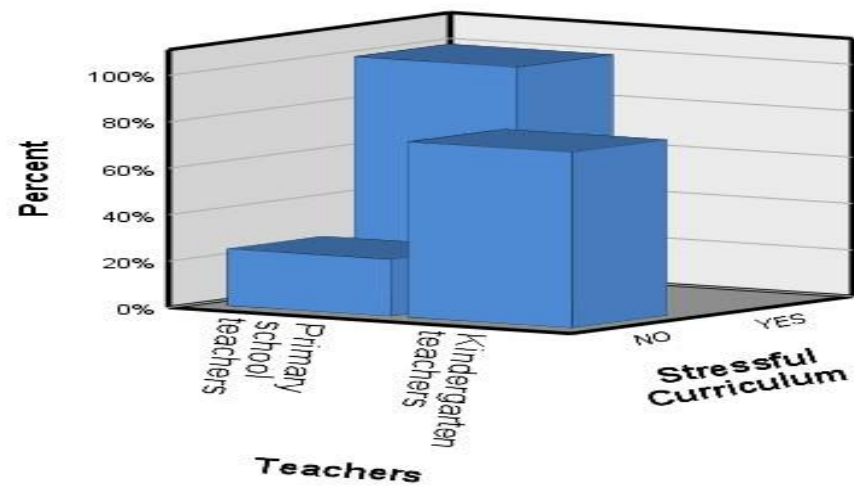

Bar graph 2. Kindergarten and Primary School Teachers -Stressful Curriculum

For teachers work in education for 11 to 20 years, it was noted that they recorded a higher rate for difficulties in implementing differentiation the demanding preparation. The large number of students per classroom is a major difficulty for teachers with a percentage (41.8\%) and less for kindergarten teachers (23.5\%). The lack of teaching time was seen as a difficulty for teachers $(39.2 \%)$ to a significant extent compared to kindergarten teachers (4.6\%). In an open-ended question about the difficulties encountered in implementing differentiated instruction, 23 in 306 (4.24\%) teachers responded the lack of co-operation among teachers.

\section{Discussion}

The highlighting of the difficulties faced by primary school teachers and kindergartens during the implementation of differentiated instruction was the central focus of this research. The inadequate teachers' knowledge, the timetable, the fear of applying something new, the specialized knowledge that is required, the lack of equipment, means, materials and space, the inadequate experience and the bureaucratic structure of the Greek educational system may be a hindrance in implementing any innovative action and adopting an alternative teaching approach (Karabetsou, 2017: 133). In the present study, the lack of time for preparation, the demanding preparations for differentiated instruction, as well as the lack of supportive tools and materials were noted as the main difficulties. However, one of the basic conditions for applying differentiated instruction is the creation of appropriate supporting equipment for the conduction of activities - hierarchy of activity sheets, work of gradual difficulty, etc. - this process is quite demanding and timeconsuming (Christnsen, 1993; Valiandes \& Koutselini, 2008). For the successful implementation of differentiated 
instruction the traditional, conventional, and easy are discarded, while effort, dedication and patience are required (Valiandes \& Koutselini, 2008).

A point that we examine in this research was also the experience and level of teacher education in relation to the difficulties encountered in implementing differentiation. It was found that teachers with postgraduate studies encountered fewer difficulties in implementing differentiated teaching. According to Rodriguez's (2012) research, the breadth of knowledge and didactic experience are key prerequisites for successfully implementing differentiation. Research has revealed that teachers who have completed postgraduate studies are more often applying Differentiation to day-to-day instruction, as evidenced by Affholder (2003), differentiated strategies are used by more experienced teachers as they are better aware of the content of the curriculum and have been trained in the implementation of alternative teaching strategies and techniques.

Moreover an interesting point is the teachers' cognitive competence regarding the theoretical framework and the practical application of differentiation but its limited application to the daily teaching practice. Among the reasons for the low and modest level of implementation of differentiated instruction, teachers argue that they usually follow their own way of teaching as they are not really aware of the actual implementation process. This position is also substantiated by research (Yenmez \& Ozpmar, 2017), as it is found that the theoretical knowledge of differentiation from practical application is far removed. It is assumed that there is a significant deviation between beliefs and practices, which demonstrates that theory deviates significantly from practice and ultimately theoretical knowledge from practical application (Wang et al., 2008). Teachers often choose to adopt features and practices that are familiar to them from their student lives, from their own teachers, and form an image or model of a teacher who seeks to apply themselves (Cole \& Knowles, 1993).

The research data have greatly highlighted the insecurity feeling by teachers in implementing the new philosophy of differentiation. Researchers have documented the teachers' insecurity and anxiety to apply innovations to school as they have often found that some educational changes have proved frustrating, deceptive and problematic (Majhanovich, 2002). Although teachers have a positive impression and are willing to adopt new teaching approaches, however they are reluctant to apply them because they report their concern and doubts about the outcome (Siakoveli, 2011, p. 49).

The lack of motivation is also an important inhibiting factor in the successful implementation of differentiation, which is also confirmed by Adlam's research (2007), who highlighting it as a prerequisite.

The research findings revealed that teachers faced difficulties because of the difficult school program and the requirements of the curriculum, while kindergartens seem to have a more flexible curriculum. The majority of teachers referred to the syllabus quantity and the number of requirements resulting from the curriculum, which is indirectly confirmed by other researches (Skaalvik \& Skaalvik, 2010). Basic reasons for the difficulty of adopting innovative programs, applying alternative teaching practices and shaping stressful working conditions in primary education are the burdensome program and the requirements of teaching (Pines, 1996 Maphalala, 2014). For the kindergartens, the curriculum appears to

have been broadened to reflect macro-level and micro-level processes, while coexisting with historical-cultural influences (Sakellariou, 2010). 
It has been noticed that teachers encounter difficulties in their work because of the large number of pupils per class, as well as the parents' intervention on issues related to education something that is also know by the bibliography (Vergides, 2008).

Regarding the recording of the difficulties in implementing differentiated instruction, the lack of teachers' willingness to cooperate was recorded in an open-ended question. The cooperation between school teachers is usually limited and degraded, while the concepts of the autonomy and independence of the teacher (Hardgreaves, 1994) are of primary importance. Research has shown that teachers feel professionally and emotionally isolated from their colleagues as the relationships that prevail are superficial and do not show willingness to cooperate (Graves, 2001; Patterson \& Rolheiser, 2004).

\section{Conclusion}

In conclusion, this research study examined the beliefs of kindergarten and primary school teachers on the difficulties of implemented functionality of Differentiated Instruction. We propose the provision of possibilities for linking the theoretical knowledge with practical application of Differentiated Instruction. Furthermore, it is important the continuous training of teachers on Differentiated Instruction and the provision of appropriate supporting equipment. The redefinition of the perceptual system and the revision of beliefs are a major challenge for teachers to adapt their teaching and the application of differentiated instruction (De Neve et al., 2015 Wan, 2016). The school, with the implementation of innovations and alternative teaching approaches, can work constructively in addressing the social and pedagogical challenges of teachers in order to make the most effective contribution to teaching and learning students.

\section{References}

Adlam, E. (2007). Differentiated Instruction in the Elementary School: Investigating the Knowledge Elementary Teachers Possess when Implementing Differentiated Instruction in their Classrooms. University of Windsor, Canada.

Affholder, L. (2003). Differentiated instruction in inclusive elementary classrooms. Unpublished Ed.D Thesis: University of Kansas.

Anderson, K. M. (2007). Differentiating instruction to include all students. Preventing School Failure, 51(3), 49-54.

Boyle B, Lamprianou I \& Boyle T 2005. A longitudinal study of teacher change: What makes professional development effective? Report of the second year of the study. School Effectiveness and School Improvement, 16:1-27.

Broderick, A., Metha-Parekh, H., \&Reid, D. K. (2005). Differentiated instruction for disabled students in inclusive classrooms. Theory into Practice, 44(3), 194-202.

Çakır, Ö. \& Alıcı, D. (2009) Seeing Self as Others See You: Variability in Self-efficacy Ratings in Student Teaching. Teachers and Teaching, 15(5), 541-561.

Callahan, C., Tomlinson, C., Moon, T., Brighton, C., \& Hertberg, H. (2003). Feasibility of high end learning in the middle grades. Charlottesville: University of Virginia, National Research Center on the Gifted and Talented. 
Carolan, J., \& Guinn, A. (2007). Differentiation: Lessons from master teachers. Educational Leadership, 64(5), 44.

Chan, C.W.M, Chang, R. M. L., Westwood, P. \& Yuen, M. (2002). Teaching adaptively: How easy is it in practice? A perspective from Hong Kong. Asia-Pacific Educational Researcher.11, 1,27-58.

Christensen, T. (1993). Individualizing reading assignments in large class language study. Journal of Hokusei Junior College, 29, (pp. 85-101). (ERIC Document Reproduction Service No. ED346082)

Cohen, L., Manion, L., \& Morrison, K. (2007). Research methods in education (6th Edition). London: Routledge.

Cole, A.L. \& Knowles, G.J. (1993). Shattered images: Understanding expectation and realities of field experience. Teaching and Teacher Education. 9(5/6), 457- 471.

De Neve, D., Devos, G. \& Tuytens, M. (2015). The Importance of Job Resources and Self-efficacy for Beginning Teachers' Professional Learning in Differentiated Instruction. Teaching and Teacher education, 47, 30-41.

Douglas, O., Reese-Durham, N., \& Smith Burton, K. (2008). Appropriate Grade Level: K-12. Journal of Instructional Psychology, 35(2), 182-187.

Erotocritou Stavrou, Th., \& Koutselini, M. (2015). The active involvement of teachers in action research for differentiation of the teaching-learning process: Understanding the needs of students and weaknesses of the curriculum. Journal of Education \& Social Policy, 2(2), 97-104.

Erstad, O., Eickelmann, B., \& Eichhorn, K. (2015). Preparing teachers for schooling in the digital age: A meta-perspective on existing strategies and future challenges. Education and Information Technologies, 20(4), 641- 654

Graves, D. (2001). Build energy with colleagues. Language Arts, 79 (1).http://www.coloradocfg.org/document/GravesEnergyCollegiality.pdf

Hanushek, Eric A. (2005). The Economics of School Quality. German Economic Review 6 (3): 269286. Hargreaves, A. (1994). Changing Teachers, Changing Times: Teachers' work and culture in the post modern age. London: Cassell.

Karambetsou, S. (2017). The school principal's contribution to the Implementation ofinnovative programs in education: the school principals' views from the Prefecture of Magnesia. (in Greek). King-Shaver, B. (2008). Differentiated instruction: The new and not so new. California English, 13(4), 6-8.

Koellner, K.\& Jacobs, J. (2015). Distinguishing Models of Professional Development: The Case of an Adaptive Model's Impact on Teachers' Knowledge, Instruction, and Student Achievement. Journal of Teacher Education, 66 (1) ,51-67

Koutselini, M. (2006). Differentiation of Teaching - Learning in mixed ability classes: Philosophy and concept approaches and applications. Volume A. Nicosia.

Koutselini, M. (2008). Listening to students' voices for teaching in mixed ability classrooms: Presuppositions and considerations for differentiated instruction. Learning and teaching, 1(1), 2008, 17-30.

Koutselini, M. \& Valiande, St. (2009). Techniques and principles underlying Differentiated Instruction, SDE (=Staff Development for Educators), National Conference on Differentiated Instruction, July 19-22, 2009 - Las Vegas.

Koutselini, M. (2014). Empowering principals and teachers to develop participatory teacher leadership: 
Towards the meta-modern paradigm of teacher development. In C. Craig, \& L. Orland-Barak (Eds.), International Teacher Education: Promising Pedagogies of Teacher Leadership, 22(2), (pp. 71-87). U.S.A.: Emerald.

Koutselini, M., \& Patsalidou, Fr. (2015). Engaging school teachers and school principals in an action research in-service development as a means of pedagogical self-awareness. Educational Action Research.

Lewis, S. G., \& Batts, K. (2005). How to implement differentiated instruction? Adjust, adjust, adjust. Journal for Staff Development, 26(4).

Majhanovich, S. (2002). Conflicting visions, competing expectations: control and deskilling of education -a perspective from Ontario. McGill Journal of Education, 37(2), 159-176.

Maphalala, C.M. (2014). The Manifestation of Occupational Stress in the Teaching Profession: The Unheeded Voices of Teachers. Mediterranean Journal of Social Sciences, 5(1), 77-88

Njagi, M., W. (2014) , Teachers' Perspective Towards Differentiated Instruction Approach in Teaching and Learning of Mathematics in Kenya. International Journal of Humanities and Social Science, 4(13), 236241.

Nicolae, M. (2013). Teachers Beliefs as the Differentiated Instruction Starting Point: Research Basis. Procedia-Social and Behavioral Sciences, 128, 426-431.

Panteliadou, S., Chideridou-Mandradi, A. \& Papa, D. (2017). Difficulties and challenges in the development of differentiated teaching projects. Paper presented at the International Conference titled: Differentiation of instruction for teachers' professional development and students' success, May, 26-27, 2017, Nicosia, Cyprus.

Patterson, D., \& Rolheiser, C. (2004). Creating a culture of change. National Staff Development Counsil, 25

(2).

http://bbaplc.wikispaces.com/file/view/Creating+a+Culture+of+Change.pdf

Pines, A.M. (1996). Couple burnout. New York: Routledge.

Robinson, L., Maldonado, N. \& Whaley, J., (2014).Perceptions about Implementation of Differentiated Instruction. Paper presented at the Annual Mid-South Educational Research (MSERA) conference November 7, 2014, Knoxville, Tennessee

Rodriguez, A. (2012). An Analysis of Elementary School Teachers' Knowledge and Use of Differentiated Instruction. United States: Olivet Nazarene University

Roy, A., Guay, F., Valois, P. (2012). Teaching to Address Diverse Learning Needs: Development and Validation of a Differentiated Instruction Scale. International Journal of Inclusive Education.

Sakellariou, M. \& Mitsi, P. (2017). Investigation of the attitudes and beliefs of prospective Kindergarten and Primary school teachers on the implemented functionality of Differentiated Teaching within the framework of Teaching Practice. Paper presented at the International Conference titled: Differentiation of instruction for teachers' professional development and students' success, May, 26-27, 2017, Nicosia, Cyprus.

Sakellariou, M. (2010). Curricula and moral education. A postmodern challenge. In M. Sakellariou, M. Zebilas \& A. Petrou (Ed.). Morality and education. Dilemmas and prospects. Athens: Kritiki (in Greek) 
Santangelo, T. \& Tomlinson, C. A. (2012). Teacher Educators' Perceptions and Use of Differentiated Instruction Practices: An Exploratory Investigation. Action in Teacher Education,34(4), 309-327.

Schumm, J., \& Vaughn, S. (1991). Making adaptations for main-streamed students: General classroom teachers' perspectives. Remedial and Special Education, 12(4), 18-27.

Scott, B.J., Vitale, M.R. \& Masten, W.G. (1998). Implementing instructional adaptations for students with disabilities in inclusive classrooms. Remedial and Special Education, 19,2, 106119.

Simpson, M., \& Ure, J. (1994). Studies of differentiation practices in primary and secondary schools(Interchange Report \#30).Edinburgh, Scotland: Scottish Council for Research in Education.(ERIC Document Reproduction Service No. ED 380 196)

Skaalvik, E.M. \& Skaalvik, S. (2010). Teacher self-efficacy and teacher burnout: A study of relations. Teaching and Teacher Education, 26,1059-1069.

Smit, R. \& Humpert, W. (2012). Differentiated Instruction in Small Schools. Teacher and Teaching Education, 28, 1152-1162.

Theofilides, Ch. (2009). Cracks in the iceberg of traditional teaching. Athens: Ed. Gregory [in Greek] Tobin, R.\& Tippett, C., D. (2013). Possibilities and Potential Barriers: Learning to Plan for Differentiated Instruction in Elementary Science. International Journal of Science and Mathematics Education, 12(2), 423-443.

Tomlinson, C.A. (2003). Differentiating Instruction in Response to Student Readiness, Interest, and Learning Profile in Academically Diverse Classrooms: A Review of Literature. Journal for the Education of the Gifted, 27 (2/3), 119-45.

Tomlinson, C. (2005). Quality curriculum and instruction for highly able students. Theory into Practice, 44

(2), 160-166.

Tomlinson, C. A. (2014). The Differentiated Classroom: Responding to Needs of all learners, 2nd Edition.

Yenmez, A.A. \& Ozpınar I., (2017). Pre-Service Education on Differentiated Instruction: Elementary Teacher Candidates' Competences and Opinions on the Process. Journal of Education and Practice .Vol.8, No.5, ISSN 2222-1735

Ysseldyke, J., Thurlow, M.L., Wotruba, J.W. \& Nania, P.A. (1990). Instructional arrangements: Perceptions from general education. Teaching Exceptional Children, 22, 4,4-8.

Valiandes, S. \& Koutselini, M. (2008). Implementation of Differentiated Teaching in Mixed Skills Classes:

Requirements and Issues to Discuss. Proceedings of the Pancyprian Conference of the Pedagogical Society of Cyprus. Nicosia. Cyprus

Valiandes, S. \& Koutselini, M. (2009). Implementation of differentiated teaching-learning using the textbooks. XIII International Conference of Pedagogical Society of Greece. loannina - November 2009 [in Greek].

Valiandes, S \& Neophytou, L. (2017). Differentiated Instruction. Functional and effective implementation. Athens: Pedio 
Valiandes, S. (2015). "Evaluating the Impact of Differentiated Instruction on Literacy and Reading in Mixed Ability Classrooms: Quality and Equity Dimensions of Education Effectiveness." Studies in Educational Evaluation 45: 17-26.

Vergides, D. (2008). Teacher problems in the performance of their work. University of Patra (in Greek).

Wan, S. W. Y. (2016). Differentiated Instruction: Hong Kong Prospective Teachers' Teaching Efficacy and Beliefs. Teachers and Teaching, 22(2), 148-176.

Wang, J., Elicker, J., McMullen, M., \& Mao, S. (2008). Chinese and American preschool teachers' beliefs about early childhood curriculum. Early Child Development and Care, 178(3), 227-249.

Westwood, P. (2002). Are we making teaching too difficult? A critical look at differentiation in the classroom. Hong Kong Special Education Forum 5, 1,13-29.

Westwood, P. (2001). Differentiation as a strategy for inclusive classroom practice: Some difficulties identified. Australian Journal of Learning Disabilities, 6, 1,5-11.

Wormeli, R. (2011). Differentiated instruction: Setting the pedagogy straight. Middle Ground, 15(2), $39-40$. 